\title{
Prediction Skills, Reading Comprehension and Learning Achievement in Vihiga County Kenya. Addressing Constraints and Prospects
}

\author{
Mary Susan Anyiendah ${ }^{1}$, Paul Amolloh Odundo ${ }^{1} \&$ Agnes Kibuyi ${ }^{1}$ \\ ${ }^{1}$ Department of Educational Communication \& Technology, University of Nairobi, P.O. Box 30197-00100, \\ Nairobi \\ Correspondence: Mary Susan Anyiendah, Department of Educational Communication \& Technology, University \\ of Nairobi, P.O. Box 30197-00100, Nairobi.
}

Received: July 21, 2020

Accepted: September 23, 2020

Online Published: September 28, 2020

doi: 10.5539/elt.v13n10p139

URL: https://doi.org/10.5539/elt.v13n10p139

\begin{abstract}
Prediction skill may be used in reading comprehension passages as encapsulated in interactive approach instruction. Prediction skills assist learners to decode the meaning of comprehension passages by constructing guesses about the contents of texts to be read in comprehension passages. Learners in Vihiga County register low achievement in English language examinations than peers in neighbouring counties over the years. The performance is much weaker in comprehension passages than grammar sections. Although there are low grades, the nexus between use of prediction skills and learners' achievement in reading comprehension passages has not been assessed. This study applied the Solomon Four Non-Equivalent Group Design to obtain primary data from 279 primary school learners and 8 teachers in 2017. Multiple linear regression used generated two models, one for the experimental group (Model 1) and one for the control group (Model 2). Findings indicate that the influence of prediction skills on learner achievement in reading comprehension passages was significant in experimental, but insignificant in the control groups. However, influence was stronger in the experimental than in the control groups, suggesting that training English language teachers on correct application of prediction skills improves learner achievement in reading comprehension passages. The study recommends need to: sensitise teachers on textbook usage, while supplementing with improvised materials; guide learners through titles; as well as update teacher training curriculum by integrating inter alia, emerging instructional methods embracing Information and Communication Technology and entrenching innovation in resource mobilization and use.
\end{abstract}

Keywords: prediction skills, interactive approach instruction, reading comprehension passages, innovation of resources, learner achievement

\section{Introduction}

The education policy sets English language as medium of instruction, learning and evaluation processes in the education system in Kenya (Roy-Campbell, 2014). More overtly, the National Commission on Educational Objectives and Policies of 1976 in Kenya (the Gachathi Commission) recommended that English language be introduced in the first three years of primary education, and as the medium of instruction in class four through the school system (Wamalwa and Wamalwa, 2014; Piper et al. (2018); Gudu, 2015). Despite this, primary schools begin instructing learners using English language from class one to raise the level of language competency for high academic achievement in upper primary (Kamwangamwalu and Tovares, (2016, as cited by Gudu, (2015). Similarly, Kaburi (2019) and Wandera and Farr (2018) confirm that learners' proficiency in written and spoken English improves learners' performance across subjects taught and examined at various tiers of the school system.

Reading proficiency assists learners improve aptitude in English language. As cited by Wixson (2017), Glenberg (2017) describe reading as a process of decoding and comprehending written text or symbols for better performance. This according to Odundo, Ganira and Ngaruiya (2018) is dependent on teacher instructional management skills coupled with mastery of content and use of variety of instructional pathways. Whereas decoding involves identifying and connecting letter strings to corresponding units of speech that make sense of texts or symbols, comprehension entails higher-order cognitive and linguistic reasoning, which allow learners to extract and construct meaning of written language or symbols (Wixson, 2017). To achieve this, readers interact 
with written matter, make speculative conjectures about meaning of texts and decode to either confirm or negate conjectures. This makes reading an active process that goes beyond identification of matter to establishing meaning in isolation and in context (Chen, 2018). The extent to which readers interact with texts and correctly predict the meaning of words depends on individual's cognitive knacks. However, instructional methods applied by teachers play a greater role in influencing and motivating learners to engage with English text passages to improve comprehension skills. As noted by Anyiendah and Odundo, (2017), such skills are essential for learners' understanding, interpretation and response to examination questions resulting in better performance.

The interactive approach stands out as an effective method used by teachers to encourage learners' interaction with texts, as well as activate comprehension processing skills and ability to construct the meaning of written language or symbols (Nguyen, 2016; Wixon, 2017; Chen, 2018). In this regard, learners instructed using interactive approach demonstrate outstanding dexterity in several areas. First in decoding the meaning of words used in comprehension passages. Predicting the meaning of texts, summarising huge texts without changing or losing the original meaning, connecting texts to background knowledge, as well as generating questions and answers on the context of texts (Nguyen, 2016; Wixon, 2017; Misra et al., 2018).

Prediction is one of the comprehension processing skills anchoring interactive approach instruction (Ngyen, 2016, 2017; Willyford et al., 2013; Haley and Austeen, 2013). Learners need prediction skills to understand text passages and improve performance in reading comprehension. Application of prediction skills in reading enables learners to make guesses about the meaning of texts before reading, after which comparing own predictions with actual contents of such texts (Nguyan, 2016). In view of this, readers are trained to relate current knowledge with content of comprehension passages (Haley and Austine, 2013: Ganira and Odundo, 2020). When applying prediction skills, teachers and learners deploy various strategies, either in isolation or conjointly, depending on the nature of the comprehension passage. The strategies include use of pictures, titles, visualisation and anticipation guides (Wilford et al., 2013; Haley and Austine 2013).

Pictures and titles are effective in facilitating young learners' ability to recall messages and provide answers to specific questions related to the comprehension subject. Moreover visualisation requires teachers to assist learners to develop images of stories in mind as reading process is perfected. This enables learners to recall what is read and connect with real life situations. The accuracy of such mental images depends on learners' reading skills developmental level. The accuracy also improves as learners' knowledge of content deepens and broadens (Williford et al., 2013; Smith et al., 2011). Learners' prediction skills are further enhanced through the use of anticipation guides. In this case, teachers guide learners to read pre-selected statements relating to content, before reading comprehension passages. At the end of reading task, learners are taken through each statement in anticipation guide. Learners are guided to make decisions through agreeing or disagreeing with the statements, based on insights obtained from comprehension passages (Williford et al., 2013; Smith et al., 2011).

Analysis of interactive instructional approach reveals two examination; the relationship between the approach instruction and learners' academic performance. Examples of such studies include Kaburi (2019), Wandera and Farr (2018), as well as Patric et al. (2011). Specific studies that examined the relationship between specific aspects of the interactive approach instruction, such as prediction skills, and learners' performance in reading comprehension include Smith et al. (2011), Leow and Neo (2014) Park (2012) as well as Onkoba, (2014) among others.

In Kenya, studies examined relationship between learners' performance in examinations, with the aim of determining factors contributing to poor performance at the institutional, sub-county, county and national levels (Adam, 2016; Mwanda, 2016; Okongo et al., 2015). The correlation between the type of instructional methods used by teachers and learners' performance remain strong. More specifically, 'In appropriate adoption of instructional method contributes to learners' sub-optimal performance in English language at national examinations. This was confirmed by Adan (2016) and Okongo et al. (2015). 'Incorrect instructional methods' identified by Mwanda (2016: Odundo, Othuon and Ganira (2017)), as a pervasive and perpetual challenge affecting learners' performance in reading comprehension passages. As a result, only one-third $(32 \%)$ of standard six pupils could read a standard-two-level passage in English (Mwanda, 2016).

On the other hand, Aubert et al. (2017) established relationship between interactive approach instruction and learners' academic performance, while Onkoba, (2014), and Andiema (2016), have delved into the connection between prediction skills and learners' performance in reading comprehension. More specifically, Aubert et al. (2017) argued that even though one-third of teachers applied the interactive approach in comprehension reading lessons, observations suggested that in about $90 \%$ of the lessons, the method was applied incorrectly. Consequently, application of the interactive approach instruction emerged as an important issue influencing 
learners' performance in reading comprehension. Further Onkoba, (2014) indicated significant correlation between frequency with which teachers apply prediction skills and learners' scores in post-reading questions. A significant association between frequency of teachers' use of prediction skills in reading and learners' performance in post-reading tests was found by Andiema (2016) as determining learner acquisition of requisite skills.

Vihiga County in western region of Kenya has witnessed low learner achievement in examinations over time which was blamed on weak mastery of English language skills. Kenya National Examination Council (KNEC) results for the period 2011 to 2014 show that Vihiga County's performance in English language of Kenya Certificate of Primary Education (KCPE) has persistently remained lower compared to Kisumu, Kakamega and Busia (KNEC, 2011; 2012; 2013; 2014), as illustrated by Figure 1 in the same western region.

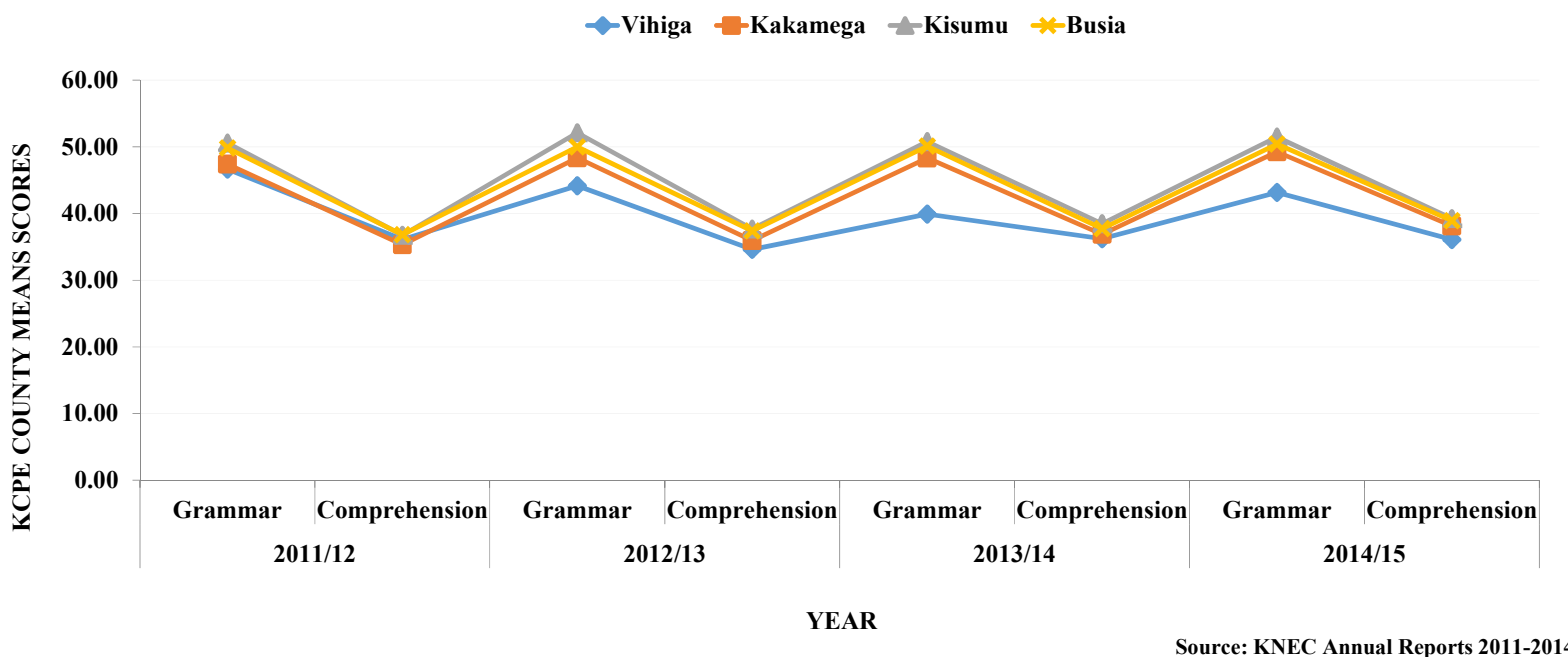

Figure 1. Learners' performance in KCPE English language

More nauseatingly, Figure 1 shows that the learners' performance in the English language examinations remains relatively lower in the comprehension section than in the grammar section (KNEC, 2011; 2012; 2013; 2014). These have captured the attention of education stakeholders in Vihiga County, including interested parties at different tiers of the school system in Kenya. In support of the position, there is no existing literature that has examined the relationship between adoption of interactive approach instruction and learners' achievement in reading comprehension for enhanced mastery of English Language in Vihiga County. Consequently, there exist weak data to inform policy, support and facilitate interventions, to improve learner acquisition of prediction skills for better achievement of English language.

To address the gap, this study was expected to generate data to inform policy and programming processes for English language teachers to access training on adoption of interactive approach instruction. Findings were to enthuse further research for accelerated mastery of English Language skills. Even though the five aspects of the interactive approach instruction, including background knowledge, learner-generated questions, summarisation, prediction and word recognition skills were covered, this article concentrates on the appropriateness of prediction skills on enhanced learners' achievement in reading comprehension for improved understanding of concepts in different context.

\section{Literature Review}

Reading is the process of identifying, extracting and constructing meaning from written language or symbols to boost understanding. This may be achieved when readers generate conjectures on the content of texts before reading, and confirming such conjectures during or at the end of the reading task for better understanding (Nguyen, 2016; Wixon, 2017). Reading is foremost process through which learners improve proficiency in English language. In Kenya, English Language is used for curriculum delivery across the school system, learners' competency in reading is essential for good performance at different tiers of education system (Kaburi, 2019; Wandera and Farr 2018; Kibet, 2017). Consequently, learners with poor reading skills may be unable to cope with the reading demands hence registering lower achievement across subject specialization. On the other hand, learners with excellent reading skills adjust quickly to reading tasks in non-lingual subjects. Kaburi, (2019), Patric et al. (2011) and Wandera and Farr (2018) argued that adoption of interactive approach instruction is an 
effective method for developing learners' comprehension reading skills, and as such, Kaburi (2019) affirmed that learners' overall academic achievement in all subjects instructed using the English language was only tenable where cognitive ability to manipulate comprehension was much stronger.

The adoption of interactive approach instruction is an amalgam model that leverages on strengths of the classical bottom-up and top-down reading approaches for enhanced mastery of comprehension skills (Wang, 2017; Ulfa, 2018). The model facilitates reading process by activating essential comprehension processing skills, including background knowledge, self-generated questions, summarisation, prediction and word recognition (Ulfa, 2018). Each component of the model encourages adoption of interaction between readers and texts in the process of extracting meaning from written language or symbols (Ulfa, 2018). Jointly, the five comprehension processing skills enhance readers' ability to understand written content, improves interactive skills and realization of meaning for sustained learner performance (Wang, 2017).

The connection between adoption of interactive approach instruction and learners' achievement resulted into two categories namely linkage between interactive approach instruction with learners' acquisition of skills and examination of each aspect of the interactive approach instruction. The prediction skills in giving meaning to comprehension passages enhance learning attainment as indicated by Kaburi (2019), Wandera and Farr (2018), Washburn et al. (2016) as well as Patrick et al. (2011), among others. Further analysis of findings on connection between prediction skills and learners' achievement in reading comprehension, including Leow and Neo (2014), Park (2012), as well as Onkoba, (2014), among others articulated the usefulness of prediction skills in enhancing learning achievement in English language content across subjects.

In addition, Kaburi (2019) established a correlation between the consistency with which teachers adopt interactive approach instruction in comprehension reading lessons and learners' achievement across subjects. Based on this, teachers who applied interactive method consistently enabled learners to be more independent in reading resulting in higher achievement. Further analysis showed that consistent application of interactive approach instruction strategy in a developing competent readers witnessed better learning achievement in comprehension. However, correctness of procedures for applying interactive approach instruction were meekly handled which provoked this study.

Washburn et al. (2016) affirmed that association exists between British learners' performance and type of instructional methods applied by teachers. In this context, learners and teachers who were using interactive approach achieved higher scores than colleagues who were guided using other methods. Findings emphasise the need for comprehension reading to be anchored on the interactive approach instruction for enhanced achievement. Moreover, Wandera and Farr (2018) established a correlation between frequency with which teachers adapted interactive approach instruction and learners' performance in all subjects taught in English.

On the other hand, Patrick et al. (2011) found association between use of interactive approach instruction by teachers and learners' proficiency in reading. To affirm this, the reading test scores showed better results than learners taught using alternative methods. Based on this, adoption of interactive approach instruction is essential for improving learners' proficiency prediction skills for reading comprehension. In Pakistan, Ghumman and Khalid, (2016) found a significant association between teachers' application of the interactive approach instruction and learners' performance which was demonstrated by higher level of proficiency in decoding content of texts for improved mastery of meaning for better understanding.

In South Africa, Nel et al. (2016), revealed a significant difference in the mean scores obtained by learners in the experimental and control groups in the adoption of interactive instruction for better attainment. More overtly, teachers who instructed using interactive approach (experimental group), learners attained higher mean scores in comprehension questions than their counterparts in control group. By implications, teachers should be supported, facilitated and motivated to correctly and consistently adapt interactive approach instruction strategy to improve learners' achievement in reading comprehension to raise learning achievement.

In an earlier study by Johnson (2014) in Australia, it was established that there is a significant reliable association between learners' application of prediction skills when reading comprehensions and resultant reading achievement, which was measured by test scores. In addition, influence association was stronger between adoption of prediction skills and knowledge of the scientific content. In this regard, high-knowledge learners obtained better scores than lower knowledge ones in scientific content. This indicates usefulness of adoption of interactive instruction in boosting learner achievement in comprehension across subject specializations.

Furthermore, Leow and Neo (2014) found a significant correlation between teachers' activation of prediction skills and leaner's' performance in comprehension test questions. More specifically discussing titles with learners before reading passages influenced learner's performance in comprehension questions. Further, the 
higher the frequency of discussing passage titles, the higher the scores obtained by struggling learners in giving correct meaning to passages. In addition, regularity of discussing titles before reading enabled learners to develop quick ideas, which facilitated prediction of the content and context of comprehension passages for better mastering. This implies that reading achievement may be constrained for struggling learners in situations where teachers fail to discuss titles before reading comprehension passages resulting in weaker mastery. If appropriately implemented, prediction skills enable learners to connect current knowledge which enhances learning attainment about comprehension with new ideas to be read about in passages.

In the United States, Park (2012) contented that visualisation as an instructional strategy consistently activate learners' prediction skills and improves reading achievement across subject specialization. More concisely, Partzaz underscored visualisation in helping learners to process visual representations of written words, symbols or objects in order to extract meaning for mastery of comprehension passages and achievement. Similar arguments were expressed by National Reading Panel (Johnson, 2017) which emphasized visualisation in motivating learners to engage with written materials, symbols or objects, while developing mental constructs of contents in subsequent sections of comprehension passages (Johnson, 2017). Despite this, its application by teachers, particularly in developing countries, remains sub-optimal occasioned by in appropriate skills among teachers; as well as shortage of access to new knowledge to motivate and support teachers to develop necessary prediction skills to perfect teaching.

Wooley (2010) argued that use of section and subsection headings caused a direct influence on skills for comprehension reading and performance across subjects. Further analysis showed consistent use of section headings draws attention of learners to succeeding contents of subsequent sections; making strategic content-area readers to identify key messages and use same knowledge to predict the contents of next sections. Moghaddam (2014) acknowledges that pausing and discussing section headings provide learners with a chance to internalise content read; thereby, facilitating higher order understanding of subsequent sections. Further analysis indicated that teachers who fail to discuss section headings, denied learners the opportunity to predict expectations in subsequent sections; which constrains comprehension of text passages among struggling learners and resulting in much lower learner achievement across subject specializations.

In Kenya, Onkoba (2014) asserted that learners who always applied applications of prediction skills when reading achieved higher scores consistently in post-reading questions than colleagues who adopted the instructional strategy occasionally. Based on this, prediction skills may be used as learning instruments to improve learners' performance in reading comprehension for better learning achievement. In support, John et al. (2017) revealed that utilisation of pictures to trigger learners' prediction skills in reading was near universal in articulating expected meaning in subsequent sections. Drawing from this, the study established association between teachers' frequency in adopting prediction in reading and learners' scores in post-reading questions. Despite the significance, most teachers continue to rely on pictures contained in syllabus books, with no supplementations such as drawings, diagrams on chalkboards, or photographs which weakens learner conceptualization lowering scores in comprehension passages and resulting in much lower learner achievement. John et al. (2017) singled out the omission as a drawback given syllabus books alone are too insufficient to assist learners make accurate predictions about comprehension passages. In addition, over-reliance on book pictures to issues of time workload, low motivation, school culture; as well as limited innovative skills among trainees and practising teachers tend to compound the problem.

Analysis in contexts suggest that prediction skills and learners' achievement in reading comprehension are conceptually connected, such that a unit change in learners' prediction skills is likely to influence a proportionate change in achievement in post-reading tests Notably though, in Vihiga County, Kenya the situation remain dive given weak learning achievement over the years. Arising from this challenge, the conceptual frame work presented in Figure 2 elaborates the perception relating causal relationship between learners' prediction skills and achievement in reading comprehension. Prediction skills was therefore set as the independent variable, while learners' achievement in reading comprehension passages was designated the dependent variable. The independent variable was unpacked using five perception statements, which aligned to specific reading practices showing learners prediction skills in subsequent sections of a comprehension passage. Besides, each perception statement was measured using a five-point scale, marked as 'strongly agree', 'agree', 'undecided', 'disagree', and 'strong disagree'. 


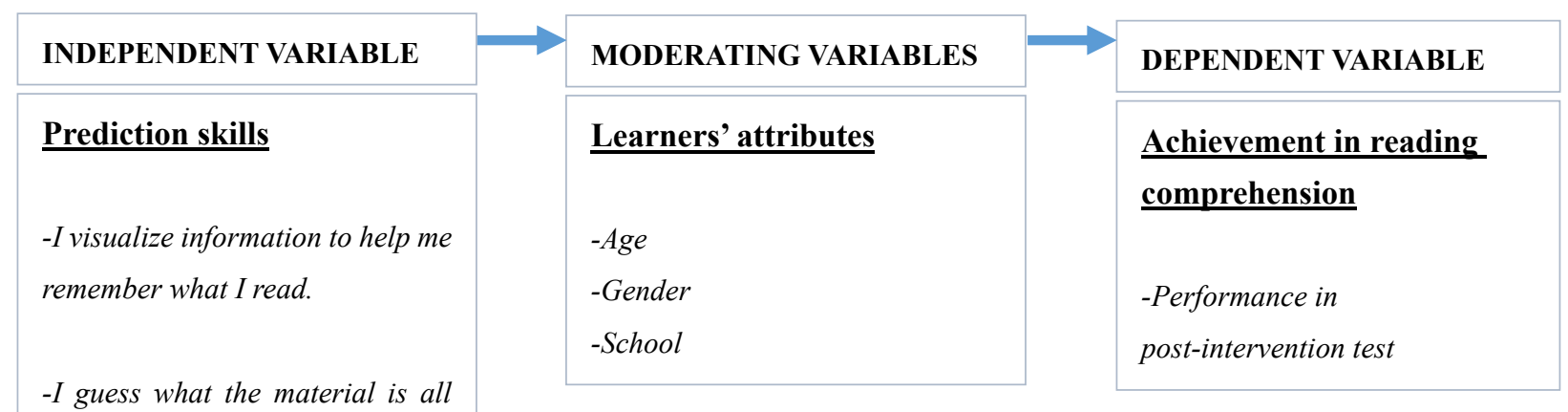

about when I read the information.

-I use pictures, tables and figures

to increase my understanding.

Figure 2. Perceived frame of prediction skills and achievement in reading comprehension

Furthermore, the dependent variable was measured as learners' performance in the post-intervention test on giving meaning to subsequent sections in comprehension passages. The framework further shows that, learners' attributes, such as age, gender, school and sub-group are likely to moderate the relationship between the application of prediction skills and learners' achievement in reading comprehension.

\section{Methodology}

The design, methods and approaches used captured, processed, analysed and interpreted the data drawn from the positivist and constructivist philosophical schools, which are complementary ontologically, epistemologically and methodologically (Castleberry and Nolen, 2018; Wagner et al., 2019). Based on the schools of thought, both quantitative and qualitative methods were applied to capture primary data on learners' prediction practices when reading texts and scores in the post-intervention test, which was designated, learners' achievement in reading comprehension passages.

The Solomon Four non-equivalent-Group Design was applied to guide the process. Drawing from the design's principles, eight public primary schools were randomly assigned into two groups: experimental and control. The experimental group included schools code-named G, H, I and J, while the control group comprised of schools K, L, M and N. Teachers of English language in the experimental group were trained on application of interactive approach instruction, while control group were not. More still, learners in schools $\mathrm{G}$ and $\mathrm{H}$ in the experimental group, and schools $\mathrm{K}$ and $\mathrm{L}$ in the control group were subjected to a pre-intervention test. After training, teachers in the experimental group were observed for a period of three months. After observation learners in all the eight schools were exposed post-intervention test. Toye et al. (2016), and Glesne (2016) provide details of application of Solomon Four non-equivalent-Group Design.

The study targeted registered 361 public primary schools in Vihiga County. Within the schools, standard six learners and teachers of English language were targeted. Standard six was targeted because it marks the point when learners start preparing for KCPE; hence, the involvement of such learners was likely to contribute positively towards preparation for final examinations. Census and purposive sampling procedures were applied at different levels in determining sample sizes in Table 1, part A. 5 Sub-Counties were involved based on principles of a census. From each sub-county, 2 schools were purposively selected, based on participation in $\mathrm{KCPE}$ for at least five years and rural-urban representation. The process yielded 12 schools, of which 4 participated in the pilot study, and 8 involved in the main study. From each school, 1 teacher of English language in standard six, was selected purposively. Besides, 420 standard six learners were involved, of which 280 participated while 140 in the pilot study. 
Table 1. Sample size determination

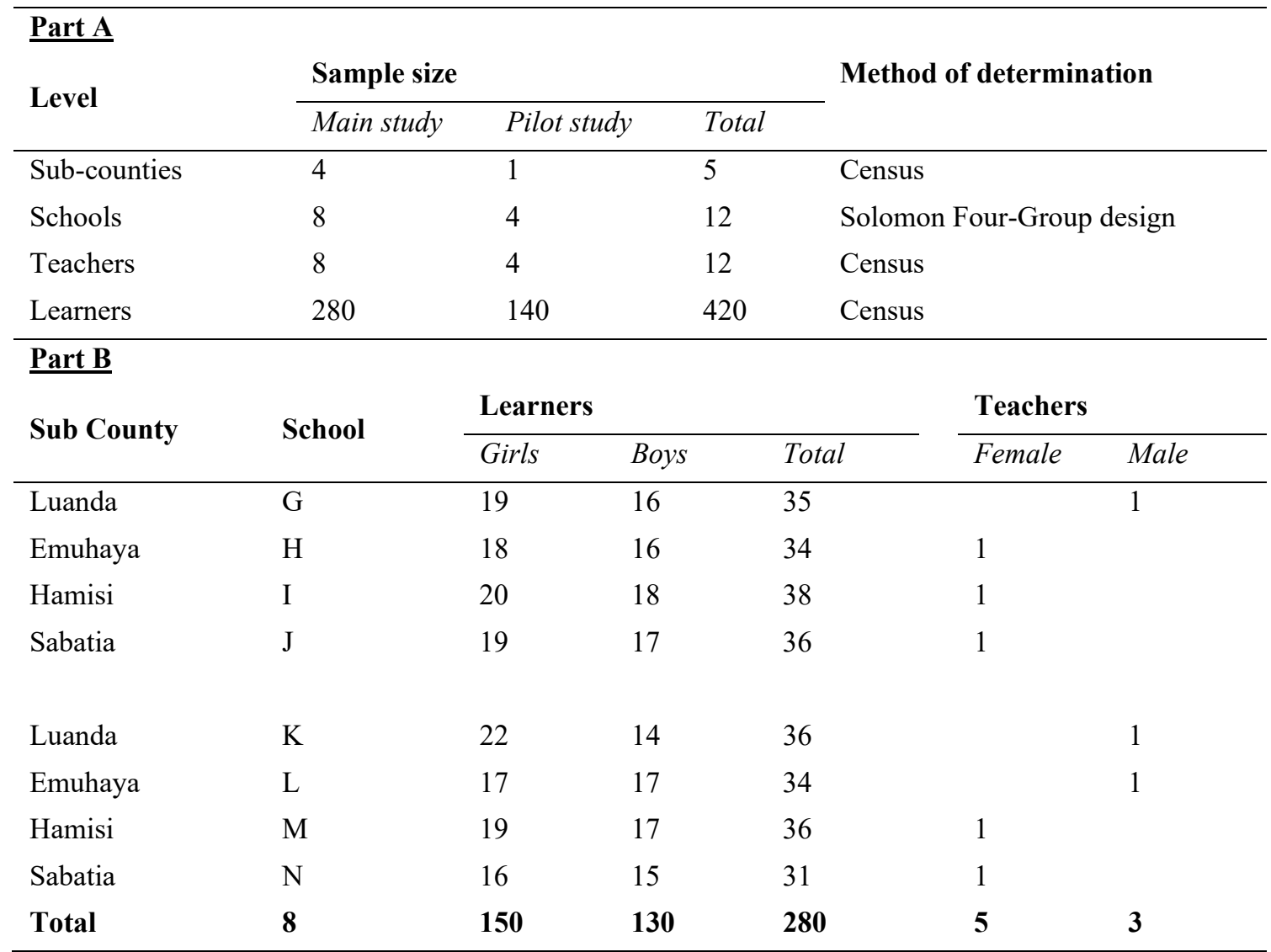

Part B Table 1 shows distribution of learners and teachers by gender. Data was sourced using questionnaires for learners, interview schedule for teachers, an observation schedule as well as pre-test and post-test tool to determine level of application of prediction skills in generating meaning from comprehension passages. The instruments were pilot-tested between January and April, 2017 in 4 schools. In total, 4 teachers and 140 learners were involved. The tools were adjusted to improve content, clarity and feasibility, based on suggestions obtained from the issues arising.

The authorization letter for data collection was obtained from the National Commission for Science, Technology and Innovation, as well as an introduction letter from the University of Nairobi to facilitate the process, which occurred between May and August, 2017. Data collection started with administration of the pre-intervention test to learners in schools $\mathrm{G}$ and $\mathrm{H}$ in the experimental group, and schools $\mathrm{K}$ and $\mathrm{L}$ in the control group. Training of teachers in the experimental group on correct application of interactive approach instruction; observation of comprehension reading lessons continued for three months. At the end of the observation period, learners in both groups were subjected to a post-intervention test to establish effect of training provided to teachers and resultant change on learners' achievement in reading comprehension passages. The questionnaires were also administered to learners and teachers in both groups to authenticate change in patterns of mastery of prediction skills for sustained learner attained.

Quantitative analysis techniques included One-way Analysis of Variance, which was used to generate mean scores; independent samples t-tests, which determined the significance of variations between scores achieved by the two groups; cross tabulations with Chi-square tests, which determined statistical associations between learners' perceptions on various reading practices and scores obtained in the post-intervention test. Lastly, linear regression analysis was performed to establish influence of prediction skills on learners' achievement in reading comprehension passages. The Statistical Package for Social Sciences (SPSS) facilitated quantitative data analysis. Furthermore, qualitative data were transcribed and subjected to thematic analysis, which identified emerging themes and sub-themes and patterns of change in learners' achievement in reading comprehension passages. Detailed information about methods applied may be accessed from: Chowdhurry (2019), Glenberg (2017), Albers (2017), as well as Mohajan (2018), who among others amplified adoption of interactive instruct as a strategy for improved achievement in comprehension passages using prediction skills. 
Social research ethical principles, which entailed obtaining informed consent from parents, before involving learners were embraced. Brief letters to parents, explaining purpose, potential benefits and need for voluntary participation to improve adoption of prediction skills is giving meaning to comprehension passages. In addition, the letter also contained a clause about the right to withdraw consent of participation for individual learners at any time before or during process. Further learners filled forms in assent forms, confirming willingness to participate voluntarily. Teachers were guided through consenting process. Lastly, all participants were assured confidentiality of the data obtained from the process.

\section{Results}

The results are clustered around univariate analysis of learners' achievement in reading comprehension passages, bivariate analysis of learners' profile and achievement in reading comprehension passages, bivariate analysis of learners' perceptions on reading practices aligned to prediction skills and achievement in reading comprehension passages, as well as multivariate analysis of prediction skills and achievement in reading comprehension passages.

\section{Learners' achievement in reading comprehension passages; univariate analysis}

The data were sourced from 279 learners, including142 (50.9\%) in the experimental group and 137 (49.1\%) in the control group. The score obtained by each learner in the post-intervention test was prescribed as 'learners' achievement in reading comprehension passages', which was the dependent variable. The analysis determined the statistical significance of variation in scores obtained by learners in experimental group and control group. The t-test for independent samples was applied in determining the significance of the difference in mean scores obtained by learners in the two groups. The results in Table 2 show that learners in experimental group obtained a mean score of $35.59(95 \%$ Confidence Interval $[\mathrm{CI}]=34.71-37.07)$; while the control group achieved a mean score of $22.32(95 \% \mathrm{CI}=21.46-23.18)$. To facilitate readability of the results in Table 2, the symbol $n$ is the sample size, $S D$ stands for standard deviation, $S E$ standard error, Sig. means significance ( $\rho$-value) and $d f$ the degree of freedom.

Table 2. Post-test scores between learners in the experimental and control groups: detailing variation

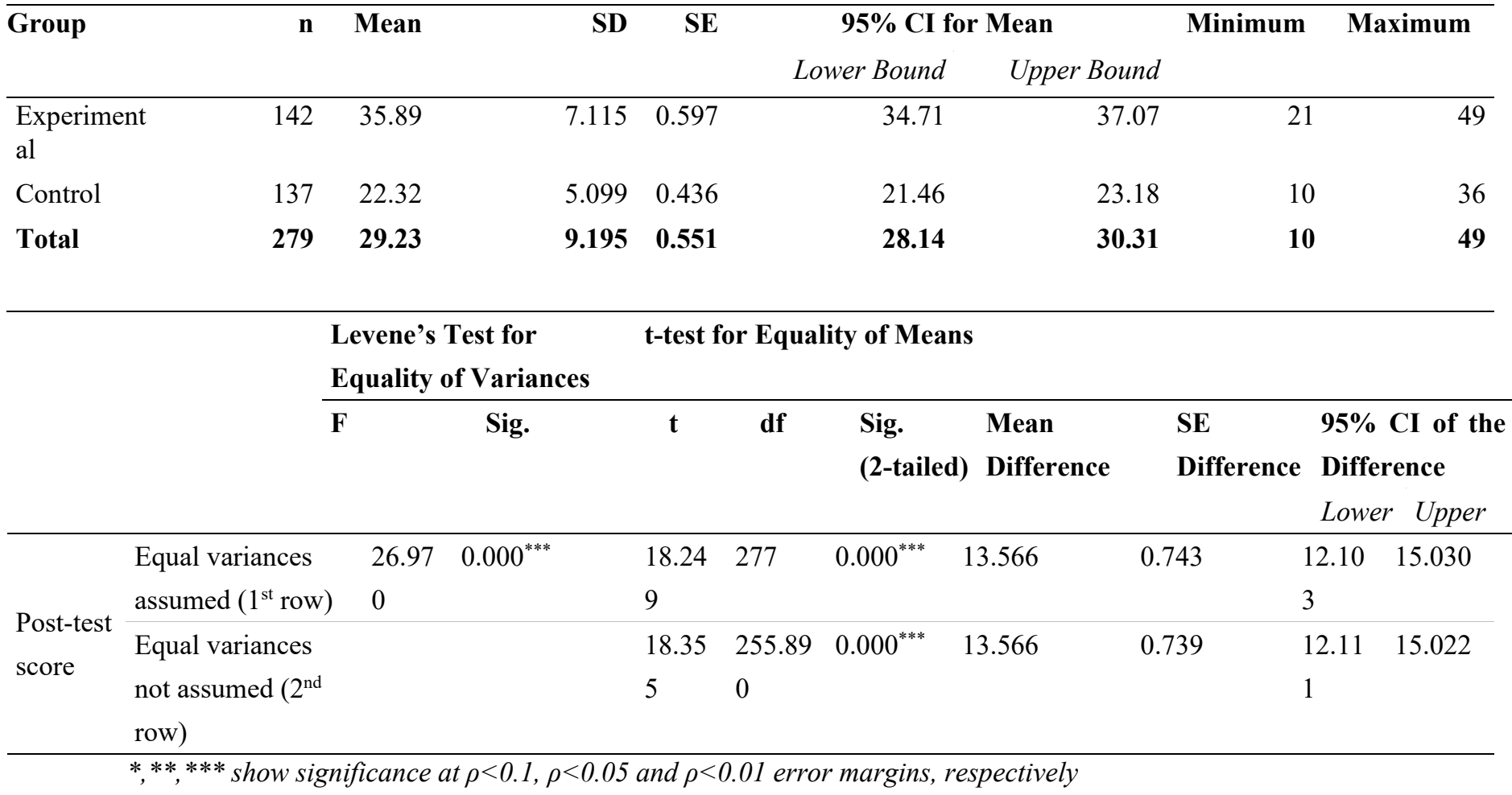

The outputs generated by the t-test for independent samples is Levene's test for equality of variance, which determining whether variances between two groups is equal or not. Variance between two groups is assumed to be equal if significance value (Sig.) for Levene's test is greater than 0.05. In such situations, results are read from the first row of Table 2. However, variances between groups is assumed as unequal when significance of Levene's test is less than or equal to 0.05 . Under such circumstances, results are read from the second row. In 
addition, the difference of the mean scores between two groups or samples is indicated by the Sig. (2-tailed) column. If the value of Sig. (2-tailed) is greater than 0.05 , then there is no significant difference between means scores obtained. In contrast, if the value of Sig. (2-tailed) is less than or equal to 0.05 , then there exist significant difference in mean scores obtained.

Drawing from the principles, Table 2 indicates that Sig. value for Levene's test was 0.000, which is less than 0.05 , thus, implying that equal variances between the two groups were not assumed; hence, results are read from the second row. Further analysis obtained a t-statistic of 18.355 with a significance value (Sig. [2-tailed]) of 0.000 , which imply up to $99 \%$ chance that mean scores obtained by learners in the experimental and control groups were different. Best on mean score obtained by learners in experimental group (35.89) which was higher than that of learners in the control group (22.32), suggesting up to $99 \%$ chance that training provided to teachers in the experimental group may have improved competence in adopting interactive approach instruction, which in turn, enhanced learners' achievement in reading comprehension passages.

\section{Profile and achievement in reading comprehension passages: bivariate analysis}

In facilitating bivariate analyses, measurement scale of scores obtained by learners in the post-intervention test was changed from interval to nominal, by recoding into four categories, calibrated as ' $<20$ marks', ' $20-29$ marks', '30-39 marks' and '40+ marks'. Resultant variable were cross-tabulated with learners' proximate attributes such as age, gender, school and sub-county at the time. Results in Table 3 show slightly more than one-half of the learners, $143(51.3 \%)$, were 12 years, $76(27.2 \%) 13$ years, while $43(15.4 \%)$ aged 14 years. Tied to achievement in reading comprehension, $64(49.6 \%)$ learners were 12 years, $32(24.8 \%) 13$ years and $20(15.5 \%) 14$ years obtained 20-29 marks. While 30-39 marks category were 28 (47.5\%) aged 12 years and $21(35.6 \%)$ were 13 years. Based on this, the cross-tabulation analysis yielded a $\chi^{2}$ of $13.082(\mathrm{df}=12 \& \rho$-value $=0.023)$, suggesting up to $95 \%$ chance that learners' achievement in reading comprehension passages significantly associated with age.

On gender perspective, Table 3 reveals that learners included 130 (46.6\%) boys and 149 (53.4\%) girls showing near party. In line with achievement in reading comprehension passage, cross-tabulation results indicate that scores $<20$ marks were 20 (48.8\%) boys and 21 (51.2\%) girls, while $22(44.0 \%)$ boys and $28(56.0 \%)$ girls achieved 40+ marks. However, association between learners' gender and achievement in reading comprehension passages was not statistically significant $\left(\chi^{2}=0.477, \mathrm{df}=3 \& \rho\right.$-value $\left.=0.924\right)$. This suggests no significant difference between scores obtained by boys and girls in the post-intervention test on reading comprehension passages.

Further Table 3, learners were drawn from 8 public primary schools, coded as G, H, I, J, K, L, M and N. Here, $38(13.6 \%)$ learners were from school I, followed by $36(12.9 \%)$ in schools $\mathrm{K}$ and $\mathrm{M}$, while $35(12.5 \%)$ were drawn from school $\mathrm{G}$. The $<20$ marks category included $15(36.6 \%)$ learners in school $\mathrm{N}$ and $14(34.1 \%)$ in school M. Learners obtaining 40+ marks were 15 (30.0\%) from schools H and I, respectively; while $11(22.0 \%)$ learners were members of school G. Based on this, the analysis revealed that learners' achievement in comprehension reading significantly associated with their schools $\left(\chi^{2}=15.719, \mathrm{df}=9 \& \rho\right.$-value $\left.=0.013\right)$. This suggests that performance in reading composition passages post-intervention test varied significantly across schools used. 
Table 3. Learners' attributes and achievement in reading comprehension passages: cross tabulation

\begin{tabular}{|c|c|c|c|c|c|c|c|c|c|c|c|c|c|}
\hline \multirow{3}{*}{$\begin{array}{l}\text { Learners' } \\
\text { attributes }\end{array}$} & \multicolumn{10}{|c|}{ Post-test scores } & \multirow{2}{*}{\multicolumn{3}{|c|}{ Test results }} \\
\hline & \multicolumn{2}{|l|}{$<20$} & \multicolumn{2}{|l|}{$20-29$} & \multicolumn{2}{|c|}{ 30-39 } & \multicolumn{2}{|l|}{$40+$} & \multicolumn{2}{|l|}{ Total } & & & \\
\hline & Freq & $\%$ & Freq & $\%$ & Freq & $\%$ & Freq & $\%$ & Freq & $\%$ & $\chi^{2}$ & $d f$ & Sig. \\
\hline \multicolumn{14}{|l|}{ Age } \\
\hline 11 years & 1 & 2.4 & 5 & 3.9 & 0 & 0.0 & 0 & 0.0 & 6 & 2.2 & & & \\
\hline 12 years & 22 & 53.7 & 64 & 49.6 & 28 & 47.5 & 29 & 58.0 & 143 & 51.3 & & & \\
\hline 13 years & 11 & 26.8 & 32 & 24.8 & 21 & 35.6 & 12 & 24.0 & 76 & 27.2 & 13.082 & 12 & $0.023^{* *}$ \\
\hline 14 years & 7 & 17.1 & 20 & 15.5 & 7 & 11.9 & 9 & 18.0 & 43 & 15.4 & & & \\
\hline 15 years & 0 & 0.0 & 8 & 6.2 & 3 & 5.1 & 0 & 0.0 & 11 & 3.9 & & & \\
\hline Total & 41 & 100.0 & 129 & 100.0 & 59 & 100.0 & 50 & 100.0 & 279 & 100.0 & & & \\
\hline \multicolumn{14}{|l|}{ Gender } \\
\hline Male & 20 & 48.8 & 62 & 48.1 & 26 & 44.1 & 22 & 44.0 & 130 & 46.6 & & & \\
\hline Female & 21 & 51.2 & 67 & 51.9 & 33 & 55.9 & 28 & 56.0 & 149 & 53.4 & 0.477 & 3 & 0.924 \\
\hline Total & 41 & 100.0 & 129 & 100.0 & 59 & 100.0 & 50 & 100.0 & 279 & 100.0 & & & \\
\hline \multicolumn{14}{|l|}{ School } \\
\hline G & 0 & 0.0 & 13 & 10.1 & 11 & 18.6 & 11 & 22.0 & 35 & 12.5 & & & \\
\hline $\mathrm{H}$ & 0 & 0.0 & 7 & 5.4 & 12 & 20.3 & 15 & 30.0 & 34 & 12.2 & & & \\
\hline I & 0 & 0.0 & 14 & 10.9 & 9 & 15.3 & 15 & 30.0 & 38 & 13.6 & & & \\
\hline $\mathrm{J}$ & 0 & 0.0 & 10 & 7.8 & 16 & 27.1 & 9 & 18.0 & 35 & 12.5 & 15.719 & 9 & $0.013^{* *}$ \\
\hline $\mathrm{K}$ & 8 & 19.5 & 19 & 14.7 & 9 & 15.3 & 0 & 0.0 & 36 & 12.9 & & & \\
\hline $\mathrm{L}$ & 4 & 9.8 & 28 & 21.7 & 2 & 3.4 & 0 & 0.0 & 34 & 12.2 & & & \\
\hline M & 14 & 34.1 & 22 & 17.1 & 0 & 0.0 & 0 & 0.0 & 36 & 12.9 & & & \\
\hline $\mathrm{N}$ & 15 & 36.6 & 16 & 12.4 & 0 & 0.0 & 0 & 0.0 & 31 & 11.1 & & & \\
\hline Total & 41 & 100.0 & 129 & 100.0 & 59 & 100.0 & 50 & 100.0 & 279 & 100.0 & & & \\
\hline \multicolumn{14}{|l|}{ Sub-county } \\
\hline Luanda & 8 & 19.5 & 32 & 24.8 & 20 & 33.9 & 11 & 22.0 & 71 & 25.4 & & & \\
\hline Emuhaya & 4 & 9.8 & 35 & 27.1 & 14 & 23.7 & 15 & 30.0 & 68 & 24.4 & & & \\
\hline Hamisi & 14 & 34.1 & 36 & 27.9 & 9 & 15.3 & 15 & 30.0 & 74 & 26.5 & 166.542 & 21 & $0.000^{* * *}$ \\
\hline Sabatia & 15 & 36.6 & 26 & 20.2 & 16 & 27.1 & 9 & 18.0 & 66 & 23.7 & & & \\
\hline Total & 41 & 100.0 & 129 & 100.0 & 59 & 100.0 & 50 & 100.0 & 279 & 100.0 & & & \\
\hline
\end{tabular}

$*, * * * * *$ show significance at $\rho<0.1, \rho<0.05$ and $\rho<0.01$ error margins, respectively

Table 3 further indicate that 74 (26.5\%) learners were drawn from Hamisi Sub-County, 71 (25.4\%) from Luanda, 68 (24.4\%) were in Emuhaya, while 66 (23.7\%) schooled in Sabatia. Based on achievement in reading comprehension passages, scores between 20-29 marks included 36 (27.9\%) in Hamisi, 35 (27.1\%) from Emuhaya and $32(24.8 \%)$ housed in Luanda. In addition, 15 (30.0\%) learners in Hamisi and Emuhaya Sub-Counties, each; as well as $11(22.0 \%)$ in Luanda scored 40+ marks. Further analysis revealed that learners' achievement in reading comprehension passages were significantly associated with sub-counties of residence $\left(\chi^{2}\right.$ $=166.542, \mathrm{df}=21 \& \rho$-value $=0.000)$. This suggests that achievement in reading comprehension passages varied significantly across the sub-counties of Vihiga County.

\section{Prediction skills \& learners' achievement in reading comprehension passages: bivariate analysis}

Prediction skills were measured using perception statements aligned to pertinent reading comprehension passages practices. The response learners indicated views on perception statement on a five-point measurement scale, calibrated as 'strongly agree', 'agree', 'undecided', 'disagree' and 'strongly disagree'. Views were then cross-tabulated against achievement in reading comprehension passages which generated different positions. 
The first perception statement asserted that 'I visualise information to help me remember what I read'. The results in Table 4 show that of the 279 learners, 107 (38.4\%) agreed, while 29 (10.4\%) agreed strongly. Contrastingly, $73(26.2 \%)$ learners voiced disagreement with the statement, while $60(21.5 \%)$ disagreed strongly. Cumulatively, further analysis show that up to $136(48.7 \%)$ learners affirmed the statement; suggesting that visualisation of information to facilitate recollection of passage contents was practiced by nearly one-half of the learners. Statement was untrue were 60 (21.5\%) implies strong disapproval.

Cross-tabulation results in Table 4 show that among the 41 learners who scored $<20$ marks, $24(58.5 \%)$ were of the view that the statement was untrue drawing from reading comprehension passage practices, while $15(36.6 \%)$ indicated that it was correct. In the category of 40+ marks $(n=50), 38(76.0 \%)$ affirmed correctness of the statement; while $10(20.0 \%)$ confuted it. More still, the category of 20-29 marks ( $\mathrm{n}=129)$ consisted of $71(55.0 \%)$ learners who said the statement was untrue about reading comprehension passage practices and 53 (41.1\%) who concurred. Cumulatively analysis revealed that learners' achievement in reading comprehension passages significantly associated with practice of visualising information to facilitate recollection of text contents at $95 \%$ confidence level $\left(\chi^{2}=25.649, \mathrm{df}=12 \& \rho\right.$-value $\left.=0.012\right)$.

Table 4. Aspects of prediction skills and achievement in reading comprehension passages

\begin{tabular}{|c|c|c|c|c|c|c|c|c|c|c|}
\hline \multirow{3}{*}{ Aspects of prediction skills } & \multicolumn{10}{|c|}{ Post-test scores } \\
\hline & \multicolumn{2}{|c|}{$<20$} & \multicolumn{2}{|c|}{$20-29$} & \multicolumn{2}{|c|}{ 30-39 } & \multicolumn{2}{|l|}{$40+$} & \multicolumn{2}{|l|}{ Total } \\
\hline & Freq & $\%$ & Freq & $\%$ & Freq & $\%$ & Freq & $\%$ & Freq & $\%$ \\
\hline \multicolumn{11}{|c|}{$\begin{array}{l}\text { I visualize information to help me } \\
\text { remember what I read. }\end{array}$} \\
\hline Strongly agree & 5 & 12.2 & 10 & 7.8 & 7 & 11.9 & 7 & 14.0 & 29 & 10.4 \\
\hline Agree & 10 & 24.4 & 43 & 33.3 & 23 & 39.0 & 31 & 62.0 & 107 & 38.4 \\
\hline Undecided & 2 & 4.9 & 5 & 3.9 & 1 & 1.7 & 2 & 4.0 & 10 & 3.6 \\
\hline Disagree & 16 & 39.0 & 36 & 27.9 & 16 & 27.1 & 5 & 10.0 & 73 & 26.2 \\
\hline Strongly disagree & 8 & 19.5 & 35 & 27.1 & 12 & 20.3 & 5 & 10.0 & 60 & 21.5 \\
\hline Total & 41 & 100.0 & 129 & 100.0 & 59 & 100.0 & 50 & 100.0 & 279 & 100.0 \\
\hline \multicolumn{11}{|c|}{$\begin{array}{l}\text { I guess what the material is all } \\
\text { about when I read the } \\
\text { information. }\end{array}$} \\
\hline Strongly agree & 8 & 19.5 & 34 & 26.4 & 14 & 23.7 & 9 & 18.0 & 65 & 23.3 \\
\hline Agree & 13 & 31.7 & 47 & 36.4 & 31 & 52.5 & 29 & 58.0 & 120 & 43.0 \\
\hline Undecided & 2 & 4.9 & 4 & 3.1 & 3 & 5.1 & 2 & 4.0 & 11 & 3.9 \\
\hline Disagree & 13 & 31.7 & 23 & 17.8 & 5 & 8.5 & 5 & 10.0 & 46 & 16.5 \\
\hline Strongly disagree & 5 & 12.2 & 21 & 16.3 & 6 & 10.2 & 5 & 10.0 & 37 & 13.3 \\
\hline Total & 41 & 100.0 & 129 & 100.0 & 59 & 100.0 & 50 & 100.0 & 279 & 100.0 \\
\hline \multicolumn{11}{|c|}{$\begin{array}{l}\text { I use pictures, tables and figures } \\
\text { to increase my understanding. }\end{array}$} \\
\hline Strongly agree & 6 & 14.6 & 38 & 29.5 & 12 & 20.3 & 18 & 36.0 & 74 & 26.5 \\
\hline Agree & 18 & 43.9 & 44 & 34.1 & 32 & 54.2 & 23 & 46.0 & 117 & 41.9 \\
\hline Undecided & 3 & 7.3 & 2 & 1.6 & 3 & 5.1 & 1 & 2.0 & 9 & 3.2 \\
\hline Disagree & 5 & 12.2 & 26 & 20.2 & 6 & 10.2 & 3 & 6.0 & 40 & 14.3 \\
\hline Strongly disagree & 9 & 22.0 & 19 & 14.7 & 6 & 10.2 & 5 & 10.0 & 39 & 14.0 \\
\hline Total & 41 & 100.0 & 129 & 100.0 & 59 & 100.0 & 50 & 100.0 & 279 & 100.0 \\
\hline \multicolumn{11}{|c|}{$\begin{array}{l}\text { I use context clues to better } \\
\text { understand what I read. }\end{array}$} \\
\hline Strongly agree & 1 & 2.4 & 10 & 7.8 & 7 & 11.9 & 7 & 14.0 & 25 & 9.0 \\
\hline Agree & 17 & 41.5 & 39 & 30.2 & 27 & 45.8 & 20 & 40.0 & 103 & 36.9 \\
\hline Undecided & 8 & 19.5 & 14 & 10.9 & 6 & 10.2 & 8 & 16.0 & 36 & 12.9 \\
\hline Disagree & 11 & 26.8 & 45 & 34.9 & 14 & 23.7 & 14 & 28.0 & 84 & 30.1 \\
\hline Strongly disagree & 4 & 9.8 & 21 & 16.3 & 5 & 8.5 & 1 & 2.0 & 31 & 11.1 \\
\hline
\end{tabular}




\begin{tabular}{lcccccccccc} 
Total & $\mathbf{4 1}$ & $\mathbf{1 0 0 . 0}$ & $\mathbf{1 2 9}$ & $\mathbf{1 0 0 . 0}$ & $\mathbf{5 9}$ & $\mathbf{1 0 0 . 0}$ & $\mathbf{5 0}$ & $\mathbf{1 0 0 . 0}$ & $\mathbf{2 7 9}$ & $\mathbf{1 0 0 . 0}$ \\
\hline $\begin{array}{l}\text { I skim the text first before I read, } \\
\text { to help my understanding. }\end{array}$ & & & & & & & & & & \\
Strongly agree & 9 & 22.0 & 33 & 25.6 & 18 & 30.5 & 12 & 24.0 & 72 & 25.8 \\
Agree & 13 & 31.7 & 43 & 33.3 & 21 & 35.6 & 30 & 60.0 & 107 & 38.4 \\
Undecided & 4 & 9.8 & 4 & 3.1 & 3 & 5.1 & 3 & 6.0 & 14 & 5.0 \\
Disagree & 9 & 22.0 & 36 & 27.9 & 12 & 20.3 & 3 & 6.0 & 60 & 21.5 \\
Strongly disagree & 6 & 14.6 & 13 & 10.1 & 5 & 8.5 & 2 & 4.0 & 26 & 9.3 \\
Total & $\mathbf{4 1}$ & $\mathbf{1 0 0 . 0}$ & $\mathbf{1 2 9}$ & $\mathbf{1 0 0 . 0}$ & $\mathbf{5 9}$ & $\mathbf{1 0 0 . 0}$ & $\mathbf{5 0}$ & $\mathbf{1 0 0 . 0}$ & $\mathbf{2 7 9}$ & $\mathbf{1 0 0 . 0}$ \\
\hline
\end{tabular}

Learners provided views on the second perception statement, which pronounced that 'I guess what the material is all about when I read the information'. Table 4 show that of 279 learners, 120 (43.0\%) agreed with the statement, while $65(23.3 \%)$ agreed strongly. Leaners who disagreed were 46 (16.5\%) while $37(13.3 \%)$ expressed strong disagreement. Cumulatively $185(66.3 \%)$ learners asserted that such statement truly reflected reading comprehension practices, about one-third, $83(29.7 \%)$ refuted insisting it was untrue.

More still, cross-tabulation showed that learners scoring $<20$ marks ( $\mathrm{n}=41), 21(51.2 \%)$ affirmed the statement, while $18(43.9 \%)$ hinted that the statement in appropriate reflection of reading comprehension passage practises specifically prediction skills. Contrastingly, category of $40+$ marks $(n=50)$, included $38(76.0 \%)$ learners opioniating correctly portrayed reading comprehension passage practices; while $10(20.0 \%)$ argued that it was incorrect reflection of the true picture. The category of 30-39 marks $(n=59)$ consisted of $45(76.3 \%)$ learners endorsing the statement with $11(18.6 \%)$ refuting the claim. Further analysis proved that learners' achievement in reading comprehension passages significantly associated with the practice of guessing the content of materials when reading at $90 \%$ confidence level $\left(\chi^{2}=19.492, \mathrm{df}=12 \& \rho\right.$-value $\left.=0.077\right)$. This confirmed that adoption of prediction skills as an instructional strategy boost mastery of reading comprehension passages generating new knowledge.

The third perception statement averred that 'I use pictures, tables and figures to increase my understanding'. Table 4 shows that whereas 117 (41.9\%) learners agreed with the statement, 74 (26.5\%) agreed strongly. However, 40 (14.3\%) learners disagreed, while 39 (14.0\%) disagreed strongly. Cumulative results indicated that of the 279 learners, 191 (68.5\%) endorsed the statement; suggesting that the use of pictures, tables and figures to increase the understanding of texts was a common practice in giving meaning to comprehension passages through prediction skills. However, 79 (28-3\%) countered the claim arguing that reading comprehension passages require multiplicity of approached including prediction skills.

Table 4 further shows that of $<20$ marks $(n=41)$, nearly two-thirds, $24(58.5 \%)$ learners, felt that the statement was consistent with reading comprehension practices; while $14(34.1 \%)$ said that the statement was inconsistent as various approaches are involved. In the category of $40+$ marks $(n=50), 41(82.0 \%)$ learners affirmed the statement, while $8(16.0 \%)$ rebutted an appropriateness wholly addressing prediction skills in reading comprehensive passages. Among those who scored 20-29 marks ( $\mathrm{n}=129), 82$ (63.6\%) learners said the statement was correct, while $45(34.9 \%)$ refuted it. Authentically drawing from cross-tabulation results, a $\chi^{2}$ of 22.921 , with 12 degrees of freedom and a $\rho$-value of 0.028 , suggesting up to $95 \%$ chance that learners' achievement in reading comprehension passages significantly associated with the use of pictures, tables and figures to increase understanding of texts and by implication using prediction skills to actualize higher mastery of concepts.

The fourth perception statement asserted that 'I use context clues to better understand what I read'. Table 4 indicate that of the 279 learners, $103(36.9 \%)$ agreed with the statement, while $25(9.0 \%)$ agreed strongly. However, 84 (30.1\%) learners disagreed, while 31 (11.1\%) disagreed strongly. Cumulative results indicate that $128(45.9 \%)$ learners affirmed the statement; meaning that use of context clues to better understand content read. Contrastingly, up to $115(41.2 \%)$ learners were non-users of context clues in reading comprehension passages for enhanced mastery of concepts. The results in Table 4 show that $<20$ marks $(n=41), 18(43.9 \%)$ backed the statement for as true; while $15(36.6 \%)$ disproved arguing that multiplicity of method may have been used indirectly to compliment prediction skills. Among scoring 40+ marks $(n=50), 27(54.0 \%)$ upheld the statement, while $15(30.0 \%)$ countered the position as untrue. In the 30-39 marks $(n=59)$ category, $34(57.6 \%)$ learners affirmed that the statement was correct, while $19(32.2 \%)$ by indicating use of variety of procedures of approaches during same session. Consequently, analysis revealed that learner achievement in reading comprehension passages was associated with practice of using context clues to better understand what reads, at $90 \%$ confidence level $\left(\chi^{2}=19.088, \mathrm{df}=12 \& \rho\right.$-value $\left.=0.086\right)$ which improved mastery of concepts alongside acquisition of prediction skills. 
The fifth perception statement, postulated that 'I skim the text first before I read to help my understanding'. In support, Table 4 shows that learners who agreed with the statement were 107 (38.4\%), and agreed strongly were $72(25.8 \%)$. However, $60(21.5 \%)$ learners disagreed with the statement, while $26(9.3 \%)$ disagreed strongly. Cumulatively, the analysis show that of the 279 learners, 179 (64.2\%) acknowledged skimming texts before reading for better understanding, while $86(30.8 \%)$ refuted the proposition. Further analysis show that of the 41 learners obtaining <20 marks, $22(53.7 \%)$ affirmed the statement; while $15(36.6 \%)$ countered appropriateness as instructional strategy. The $40+$ marks category $(\mathrm{n}=50)$, consisted of $42(84.0 \%)$ learners averring the statement, yet $5(10.0 \%)$ opionated it was incorrectly. Among structured who scored 30-39 marks $(n=59), 39(66.1 \%)$ learners upheld the statement appropriate strategy, while 17 (28.8\%) refuted authentically. Based on this, prediction skills was demonstrated as positively influencing learners' achievement in reading comprehension passages and significantly associated with the practice of skimming texts before reading to facilitate understanding, at $95 \%$ confidence level $\left(\chi^{2}=22.204, \mathrm{df}=12 \&\right.$ a $\rho$-value $\left.=0.035\right)$.

The five reading comprehension passages practices in Table 4 were aggregated to generate optimal estimates regarding the consistency with which learners applied prediction skills when reading comprehension passages. The output, which was measured using five ordinal categories, marked as, 'very consistent', 'consistent', 'undecided', 'inconsistent' and 'very inconsistent', was cross-tabulated with learners' group. The process was used to determine variation between learners in experimental and control groups concerning consistency in using prediction skills when reading comprehension passages. Figure 3 shows that of the 279 learners, 108 (38.7\%) were consistent in applying prediction skills in reading comprehensive passages, while $27(9.7 \%)$ were very consistent. Contrastingly, $73(26.2 \%)$ learners were inconsistent in deploying prediction skills when reading comprehension passages, while $16(5.7 \%)$ were very inconsistent in doing so which explain inability for learners to gain above average competences in contextualizing meaning for improved attainment.

\section{$\llbracket$ Experimental $(n=142) \quad \square$ Control $(n=137) \quad \square$ Total $(n=279)$}

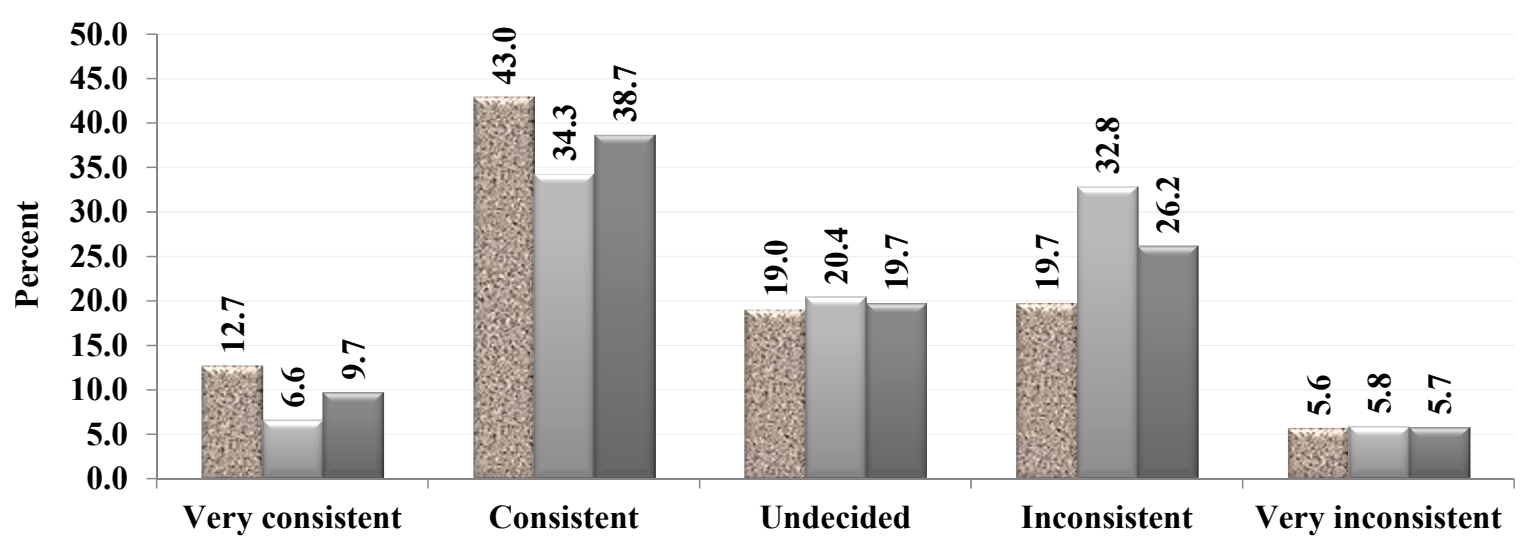

\section{Learners' aggregated views}

Figure 3. Learners' aggregated perceptions application of prediction skills and reading comprehension passages

Learner aggregated perceptions that were consistent in applying prediction skills when reading comprehension passages included $61(43.0 \%)$ in experimental group against 47 (34.3\%) in control group. Besides, 18 (12.7\%) learners in the experimental group against $9(6.6 \%)$ in the control group were very consistent in applying the technique when reading compression passages. However, $45(32.8 \%)$ learners in control group and $28(19.7 \%)$ in experimental group were inconsistent users of prediction skills; while $8(5.8 \%)$ in control group against another 8 (5.6\%) in experimental group were very inconsistent in doing so witnessing lower achievement in reading comprehension passages for better mastery of content.

Cumulatively, 79 (55.7\%) learners in experimental group against 56 (40.9\%) in control group were consistent in applying prediction skills when reading comprehension passages; however, $53(38.7 \%)$ in control group compared to $36(25.3 \%)$ in experimental group were inconsistent users of prediction skills. The analysis further revealed that variation between learners in experimental and control group in consistency of applying prediction skills when reading comprehension passages was significant at $90 \%$ confidence level $\left(\chi^{2}=8.705, \mathrm{df}=4 \&\right.$ a 
$\rho$-value $=0.069$ ). This suggests that more learners in the experimental than control group were consistent in using prediction skills when reading comprehension passages.

\section{Adoption of prediction skills \& learners' achievement in reading comprehension passages: multivariate analysis}

The focus was on determining learner use of prediction skills in influencing achievement in reading comprehension passages. The application of prediction skills were set as the independent variable, while learners' achievement in reading comprehension passages was designated as dependent variable. Both variables were incorporated in the regression analysis. With proximate attributes included in the regression process to moderate the influence of prediction skills on learners' achievement in reading comprehension passages the analysis generated two regression models - one for the experimental and one for the control groups.

Table 5 shows that the influence of prediction skills on learners' achievement in reading comprehension passages was positive in both models (Model 1: Beta $=0.358, \mathrm{t}=1.302$; Model 2: Beta $=0.278, \mathrm{t}=0.357$ ). Again, in both models, learners' prediction skills caused a proportionate increase in learners' achievement in reading comprehension passages. However, influence of prediction skills was stronger in experimental than in control group; which in turn, suggests that learners taught by trained teachers applied prediction skills more often, which in turn, improved achievement in reading comprehension passages. Logically trained teachers in experimental group were more effective in developing learners' prediction skills than colleagues in control schools. However, results indicate that in Model 1 variable's influence was significant at $90 \%$ confidence level ( $\rho=0.077)$; while in Model 2, the variable's influence was not significant $(\rho=0.285)$.

The implication is that application of prediction skills caused a significant influence on learners' achievement in reading comprehension passages in experimental group; while insignificant in control group. This reaffirms that trained teachers were better equipped in encouraging applying prediction skills in teaching reading comprehension passages. Based on the results, the null hypothesis $\left(\mathrm{H}_{0}\right)$, which stated that prediction skills have no significant influence on standard six learners' achievement in reading comprehension, was rejected in Model 1 for being untrue. However, the hypothesis was not rejected in Model 2 for insufficient empirical evidence to warrant such action.

Table 5. Influence of prediction skills on learners' achievement in reading comprehension

\begin{tabular}{|c|c|c|c|c|c|c|}
\hline \multirow{2}{*}{$\begin{array}{l}\text { Model } \\
\text { (1) }\end{array}$} & \multirow[b]{2}{*}{ (2) } & \multicolumn{3}{|c|}{ Unstandardized CoefficientsStandardised Coefficients } & \multirow{2}{*}{$\begin{array}{l}\mathbf{T} \\
-(6)\end{array}$} & \multirow{2}{*}{$\begin{array}{l}\text { Sig. } \\
\text { (7) }\end{array}$} \\
\hline & & $\overline{B(3)}$ & Std. Error(4) & $\operatorname{Beta}(5)$ & & \\
\hline \multirow{6}{*}{1} & (Constant) & 32.351 & 2.745 & & 5.631 & $0.000^{* * * *}$ \\
\hline & Prediction skills & 0.465 & 0.222 & 0.358 & 1.302 & $0.077^{*}$ \\
\hline & Age & 0.364 & 0.682 & 0.045 & 0.533 & 0.595 \\
\hline & Gender $^{r}$ & -0.002 & 1.200 & -0.000 & -0.002 & 0.999 \\
\hline & School $^{\dagger}$ & -1.496 & 1.198 & -0.235 & -1.249 & 0.214 \\
\hline & Sub-group ${ }^{+}$ & 4.346 & 2.665 & 0.306 & 1.631 & 0.105 \\
\hline \multirow{6}{*}{2} & (Constant) & 26.574 & 2.732 & & 4.095 & $0.000^{* * * *}$ \\
\hline & Prediction skills & 0.283 & 0.138 & 0.278 & 0.357 & 0.285 \\
\hline & Age & 0.325 & 0.405 & 0.059 & 0.801 & 0.425 \\
\hline & Gender $^{r}$ & -0.053 & 0.747 & -0.005 & -0.071 & 0.944 \\
\hline & School $^{+}$ & -1.350 & 0.740 & -0.294 & -1.825 & 0.070 \\
\hline & Sub-group ${ }^{\prime}$ & 2.770 & 1.639 & 0.273 & 1.691 & $0.067^{*}$ \\
\hline
\end{tabular}

Dependent Variable: Post-test score

$* * * * * *$ show significance at $\rho<0.1, \rho<0.05$ and $\rho<0.01$ error margins, respectively

+Converted into a dummy variable before inclusion into the linear regression analysis

The results in Table 5 echo qualitative data obtained. More specifically, qualitative data revealed a feeble relationship between learners' application of prediction skills and achievement in reading comprehension passages. More still, application of 'prediction skills' was common in experimental than in control group. The study findings revealed strategies commonly used by teachers to activate learners' prediction skills, including 
pictures, titles, section-heads and visualisation. Therefore, teachers in both groups over-relied on pictures to stimulate learners' prediction of comprehension passage contents. Further, teachers use pictures contained in textbooks, with minimal effort to source additional relevant materials in the form of drawings, diagrams on chalkboards, or photographs to boost prediction skills for reading comprehension passages. Participants hinted that inadequacy of time to seek and prepare supplementary pictures for use during reading comprehension lessons, due to heavy workload, low motivation and inappropriate school culture.

Pictures were particularly found to be useful in stimulating prediction skills as learners struggle with reading comprehension passages. In support, a participant pointed out that "I like using pictures in the textbook because even the struggling readers who never answer questions in class get an opportunity to speak. You see, all the learner needs to do is to say what is seen in the pictures. So the pictures offer support to my struggling readers as learners get a chance to answer at least a correct question during reading lessons."

Additional analysis revealed that teachers in both groups used titles to develop learners' prediction skills for sustained reading of comprehensive passages. However, application of the prediction skills strategy by both teachers and learners was common in the experimental than in control group, with variation attributed to training provided to the experimental group. Even though comprehension passages in text books have bolded titles, some teachers ignored discussing such titles as pre-reading activity for stimulating prediction skills in reading comprehension passages. Failure to apply the strategy denied learners the opportunity to connect prior knowledge with the context to be read, which constrained understanding of comprehension passages.

More still, application of section headings to inspire learners' prediction skills was minimal in the experimental but rare in the control group. Section headings enable learners to focus on the content of various sections, identifying messages and predicting contents of subsequent sections boosting reading of comprehension passages. This implies that learners not trained to pause at section headings experience difficulties remembering messages conveyed by lengthy comprehension passages.

The application of visualisation to activate learners' prediction skills was uncommon in experimental and control groups. The analysis identified lack of training on visualisation preventing teachers from using prediction skills strategy. In support, a participant stated that, "To be sincere madam, I have never heard of this skill before, and as much as I remember, I was not taught this skill at the TTC. You know most of the methods we apply in the field here, can be traced way back to our training. I can't recall learning such a skill." The findings suggest that teachers in both groups stifled learners' achievement in reading comprehension passages by depending on prior knowledge acquired from professional training, and not trying out alternative innovative approaches. The redundant use of traditional instructional strategies to activate learners' prediction skills to reading comprehension passages suggests that most teachers lack access to continuous professional development on interactive instructional methods for enhanced delivery.

\section{Summary and Conclusions}

The study intended to determine causal relationship between prediction skills and learners' achievement in reading comprehension passages. It was envisaged to generate data that could influence policy and programming decisions intended to improve the competence of English language teachers on application of interactive approach instruction in reading comprehension lessons. Data generated was further expected to motivate additional research by deepening and broadening knowledge on interactive approach instruction in facilitating leaner's' achievement in reading comprehension passages across school system.

Findings show that application of prediction skills improved learner achievement in reading comprehension passages in both groups; with stronger influence in experimental than control group, as indicated by Beta and $t$-statistic values (Model 1: Beta $=0.358, \mathrm{t}=1.302$; Model 2: Beta $=0.278, \mathrm{t}=0.357$ ). In addition, the variable's influence was statistically significant in experimental group at $90 \%$ confidence level $(\rho=0.077)$, but insignificant in control group $(\rho=0.285)$. The findings suggest that learners taught by trained teachers applied prediction skills more in reading comprehension passages and achieved higher scores in the post-intervention test. Trained teachers were more effective in developing learners' prediction skills than untrained colleagues in the control group. In view of this, the null hypothesis $\left(\mathrm{H}_{0}\right)$, postulating that prediction skills have no significant influence on standard six learners' achievement in reading comprehension passages, was rejected in Model 1 for being untrue. However, in Model 2, the null hypothesis was not rejected drawing from insufficient empirical evidence to warrant such action.

Of the four strategies used by teachers and learners to activate prediction skills, pictures were commonly applied in both groups. Notably though, teachers relied on pictures contained in textbooks, with minimal effort to source additional relevant materials in the form of drawings, diagrams or photographs. Time constraint occasioned by 
workload emerged as primary issue preventing teachers from developing supplementary pictures to use during reading comprehension lessons. Additional constraints included low motivation, negative school culture and inadequate awareness among teachers on adoption of the need for innovative approaches in developing learners' prediction skills for sustained reading comprehension passages.

The use of titles to activate learners' prediction skills in reading comprehension passages was below average in both groups, but common in experimental than control group; while use of section headings to inspire learners' prediction skills was minimal in experimental, but rare in control group. The application of visualisation was uncommon in both groups. Lack of continuous professional development on interactive instructional methods emerged to be preventing optimal adoption of titles, section headings and visualisation. Lack of training confined teachers to conventional teaching resources such as pictures contained in textbooks, while constraining innovation. Lack of training further constrained application of visualisation in comprehension reading, as teachers' training curriculum did not cover innovative approaches such as prediction skills.

The influence of prediction skills on learners' achievement in reading comprehension passages was statistically significant in experimental, but insignificant in the control group. This implies that teachers who accessed training on correctly applying interactive approach instruction were effective in developing learners' prediction skills than colleagues who did not access such training. Nonetheless, influence of prediction skills on learners' achievement in reading comprehension passages appears to be relatively weaker than other aspects of interactive approach instruction, such as background knowledge, learner-generated skills and summarisation skills. This implies that learners' prediction skills were not adequately developed, which in turn, amplifies the need to access training on application of interactive approach instruction to activate learners' prediction skills to stimulate improved learner achievement in reading comprehension passages.

Teachers' over-reliance on pictures contained in textbooks, implies that supplementary innovative resource materials such as drawings, diagrams on chalkboards and photographs were either under-used or not used at all to support development of learners' prediction skills. Even though textbooks were the most common instructional resources in classes, over-dependence on materials prevents learners from deepening knowledge reading comprehension passages. Over-dependence on textbooks narrows opportunities for innovation and critical thinking. The situation worsens where textbooks fail to cover content sufficiently or instances where such books are outdated. As pointed out by Brown (2016) textbooks are at times imperfect; hence, complete reliance may weaken activation of learners' prediction skills for accelerated reading comprehension passage.

In support, John et al. (2017) attributed overreliance on textbook pictures to inadequate awareness for innovation in developing learners' prediction skills. This amplifies the need to sensitise teachers to use textbooks cautiously, while supplementing with additional and appropriate resource materials. Addressing this issue requires stakeholders to sensitise teachers about innovation of supplementary resource materials that best fit learners' social and environmental contexts for enhanced attainment. Effective teacher of English creates and applies diverse resource materials to develop learners' prediction skills for improved reading comprehension passages. However, this requires construction of policies, including employer and school administrations to offer support such as addressing staffing issues, to assist teachers have time for innovating supplementary resource materials.

Pausing and discussing section titles assist learners to internalise content read for better understanding of texts and sustained competence in reading comprehension passages. This implies that failure to pause at section heading to digest contents were less likely to remember messages conveyed by lengthy comprehensive passages. Learners may experience difficulty in connecting existing knowledge with subsequent contents covered. Leow and Neo (2014) argued that reading comprehension passages may be difficult for learners if teachers ignore discussing titles during the pre-reading phase, which in turn, is likely to affect achievement in reading comprehension passages. Consequently, teachers should be sensitised on prediction skills to guide learners through titles to stimulate connection of prior knowledge with expected reading of new comprehension passages.

Underutilisation of section headings and visualisations in comprehension reading lessons denied learners the opportunity to develop own prediction skills; thereby, undermining the level of achievement in the post-intervention test. Wooley (2010) confirms the importance of section headings indicating that teaching using this strategy positions learners as content-area readers, who use contents of proceeding section to predict content to be read in subsequent sections. The marginal application of section headings by teachers and the non-use of visualisation were attributed to lack of awareness, knowledge and requisite prediction skills. Findings suggest that teacher training curriculum does not cover in details aspects of interactive approach instruction, such as visualisation. Consequently, the findings irradiates the need to review teacher training curriculum to integrate inter alia; new instructional methods based on Information and Communication Technology (ICT), as well as 
entrenching innovation to enable teachers diversify instructional resources. It's important to note that the skills acquired by teachers during training become out-dated, particularly due to technological occasioned by immerging advancements in teaching learning pedagogy and internet demands of the job market.

To address this, teachers continuous professional development (CPD) through coaching, mentorship, refresher courses, workshops and conferences. McElearney (2019) amplifying the need for teachers to keep abreast with new teaching methods by attending refresher courses, workshops and conferences, which may sustain effectiveness in delivering relevant content using appropriate instructional methods and path ways. Nonetheless, access to CPD remains a weak to teachers particularly due to limited funding. Further, the need for innovative approaches for updating teachers' professional skills remain weak and inconsistency which lowers quality. Teacher collaboration in initiatives that establishes forums for sharing experiences, skills, challenges and solutions; as well as build a culture of solidarity in uplifting professional or ethical standards for higher learning achievement. Pharis et al. (2019) stressed significant correlation between collaboration and teachers' effectiveness in applying interactive approach instructional methods, as well as teachers' willingness to adopt new innovations such as prediction skills in teaching learning particularly reading comprehension passages.

\section{References}

Adan, A. I. (2016). Institutional factors influencing pupils' academic performance at Kenya certificate of primary examination level in public schools in Mandera East Sub-County, Kenya (Doctoral dissertation, University of Nairobi). Retrieved from http://hdl.handle.net/11295/100320

Albers, M. J. (2017). Introduction to quantitative data analysis in the behavioral and social sciences. John Wiley \& Sons. https://doi.org/10.1002/9781119290384

Andiema, N. C. (2016). Effect of Child Centred Methods on Teaching and Learning of Science Activities in Pre-Schools in Kenya. Journal of Education and Practice, 7(27), 1-9. Retrieved from http://iiste.org/Journals/index.php/JEP

Anyiendah, M. S., \& Odundo, P.A. (2017). Task-based Learning in Value Creating Education: A Case Study of Secondary Schools in Vihiga Sub-county, Kenya: With Focus on Cooperation, Tolerance, Justice and Citizenship." International Journal for Human and Social Studies, 5(6), 241-249. https://doi.org/10.1257/app.4.4.226

Aubert, A., Molina, S., Schubert, T., \& Vidu, A. (2017). Learning and inclusivity via Interactive Groups in early childhood education and care in the Hope school, Spain. Learning, Culture and Social Interaction, 13, 90-103. https://doi.org/10.1016/j.lcsi.2017.03.002

Castleberry, A., \& Nolen, A. (2018). Thematic analysis of qualitative research data: Is it as easy as it sounds? Currents in Pharmacy Teaching and Learning, 10(6), 807-815. https://doi.org/10.1016/j.cptl.2018.03.019

Chen, I. C. (2018). Incorporating task-based learning in an extensive reading programme. ELT Journal, 72(4), 405-414. https://doi.org/10.1093/elt/ccy008

Chowdhury, R. (2019). Embarking on research in the social sciences: Understanding the foundational concepts. VNU Journal of Foreign Studies, 35(1). https://doi.org/10.25073/2525-2445/vnufs.4340

Ganira, K.L., \& Odundo, P.A. (2020). Influence of Pedagogical Content Knowledge on Teacher Trainee Professional Competency at University of Nairobi, Kenya. American Journal of Education and Learning, 5(1), 1-12. https://doi.org/10.20448/804.5.1.1.12

Ghumman, M. S., \& Khalid, M. I. (2016). Effectiveness of Teaching Practices for Student's Competencies Development at Early Childhood Education (ECE) Level in Pakistan. Journal of Research \& Reflections in Education (JRRE), 10(1). https://doi.org/10.1177/183693911303800102

Glenberg, A. M. (2017). How reading comprehension is embodied and why that matters. International Electronic Journal of Elementary Education, 4(1), 5-18. https://doi.org/10.1177/0956797610385353

Gudu, B. O. (2015). Teaching Speaking Skills in English Language Using Classroom Activities in Secondary School Level in Eldoret Municipality, Kenya. Journal of Education and Practice, 6(35), 55-63. Retrieved from http://iiste.org/Journals/index.php/JEP

Haley, M. H., \& Austin, T. Y. (2013). Content-based second language teaching and learning: An interactive approach. Pearson Higher Ed. 
John, A. N., Barasa, P. L., \& Omulando, C. (2017). The use of textbook illustrations in the teaching of reading comprehension: A study of secondary schools in Kathiani District-Kenya. International Journal of Research in Social Sciences, 7(8), 101-121. https://doi.org/10.1002/tea.20378

Johnson, G. M. (2014). The ecology of interactive learning environments: Situating traditional theory. Interactive Learning Environments, 22(3), 298-308. https://doi.org/10.1080/10494820.2011.649768

Kaburi, M. M. (2019). The Relationship between Self-Efficacy and Academic Performance in Mathematics and English Language among Secondary School Students in Nyamira County, Kenya. Africa Journal of Technical and Vocational Education and Training,4(1), 221-231. Retrieved from https://afritvetjournal.org/index.php/Afritvet/article/view/96

Kamwangamalu, N., \& Tovares, A. (2016). English in language ideologies, attitudes, and educational practices in Kenya and South Africa. World Englishes, 35(3), 421-439. https://doi.org/10.1111/1467-971X.00227

Kibet, A. J. (2017). Pre-school teachers' perceptions of the influence of selected instructional factors on pupils' competency skills in public pre-school centres in Keiyo South Sub-County, Kenya (Doctoral dissertation, Egerton University).

Leow, F. T., \& Neo, M. (2014). Interactive multimedia learning: Innovating classroom education in a Malaysian university. Turkish Online Journal of Educational Technology-TOJET, 13(2), 99-110. Retrieved from http://www.tojet.net

McElearney, A., Murphy, C., \& Radcliffe, D. (2019). Identifying teacher needs and preferences in accessing professional learning and support. Professional development in education, 45(3), 433-455. https://doi.org/10.1080/19415257.2018.1557241

Misra, I., Girshick, R., Fergus, R., Hebert, M., Gupta, A., \& Van Der Maaten, L. (2018). Learning by asking questions. In Proceedings of the IEEE Conference on Computer Vision and Pattern Recognition (pp. 11-20). https://doi.org/10.1109/CVPR.2018.00009

Mohajan, H. K. (2018). Qualitative research methodology in social sciences and related subjects. Journal of Economic Development, Environment and People, 7(1), 23-48. https://doi.org/10.26458/jedep.v7i1.571

Mwanda, G. M. (2016). Effect of Construction Instructional Methods on Learner Achievement in Biology in Secondary Schools in Homa Bay County, Kenya (Doctoral dissertation, University of Nairobi). Retrieved from http://hdl.handle.net/11295/100143

Nel, N. M., Tlale, L. D. N., Engelbrecht, P., \& Nel, M. (2016). Teachers' perceptions of education support structures in the implementation of inclusive education in South Africa. Koers, 81(3), 1-14. https://doi.org/10.19108/KOERS.81.3.2249

Nguyen, H. T. T. (2016). How does an interactive approach to literary texts work in an English as a foreign language context? Learners' perspectives in close-up. Innovation in Language Learning and Teaching, 10(3), 171-189. https://doi.org/10.1080/17501229.2014.932361

Odundo, P.A Othuon, L., \& Ganira, K.L. (2017). Assessors, School Support and Teaching Practice at the University of Nairobi Kenya: Addressing Teacher Professional Competence. World Journal of Educational Research, 4(3), 430-447. https://doi.org/10.22158/wjer.v4n3p430

Odundo, P.A., Ganira, K.L., \& Ngaruiya, B.(2018). Preparation and Management of Teaching Practice Process at University of Nairobi, Kenya: Appropriateness of Methods and Resource. International Journal of Learning, Teaching and Educational Research, 17(8), 107-128. https://doi.org/10.26803/ijlter.17.8.7

Okongo, R. B., Ngao, G., Rop, N. K., \& Wesonga, J. N. (2015). Effect of Availability of Teaching and Learning Resources on the Implementation of Inclusive Education in Pre-School Centers in Nyamira North Sub-County, Nyamira County, Kenya. Retrieved from http://iiste.org/Journals/index.php/JEP

Onkoba, M. K. (2014). Correlation between reading comprehension practices and academic performance: A case study of class three pupils in Westlands Sub-County, Kenya (Doctoral dissertation, University of Nairobi). Retrieved from http://hdl.handle.net/11295/75606

Park, J. Y. (2012). A different kind of reading instruction: Using visualizing to bridge reading comprehension and critical literacy. Journal of Adolescent \& Adult Literacy, 55(7), 629-640. https://doi.org/10.1002/JAAL.00074 
Patrick, H., Anderman, L. H., Bruening, P. S., \& Duffin, L. C. (2011). The role of educational psychology in teacher education: Three challenges for educational psychologists. Educational Psychologist, 46(2), 71-83. https://doi.org/10.1080/00461520.2011.538648

Piper, B., Zuilkowski, S. S., Kwayumba, D., \& Oyanga, A. (2018). Examining the secondary effects of mother-tongue literacy instruction in Kenya: Impacts on student learning in English, Kiswahili, and mathematics. International Journal of Educational Development, 59, 110-127. https://doi.org/10.1016/j.ijedudev.2017.10.002

Smith, M. K., Wood, W. B., Krauter, K., \& Knight, J. K. (2011). Combining peer discussion with instructor explanation increases student learning from in-class concept questions. CBE-Life Sciences Education, 10(1), 55-63. https://doi.org/10.1187/cbe.10-08-0101

Toye, F., Williamson, E., Williams, M. A., Fairbank, J., \& Lamb, S. E. (2016). What value can qualitative research add to quantitative research design? An example from an adolescent idiopathic scoliosis trial feasibility study. Qualitative health research, 26(13), $1838-1850$. https://doi.org/10.1177/1049732316662446

Ulfa, M. (2018). The Effect of Teaching by Using Interactive Approach on Reading Comprehension to The Tenth Grade Students of Madrasah Aliyah Swasta Gp. Teungoh Kota Langsa. Journal of Education, Linguistics, Literature and Language Teaching, 2(1), 39-47. Published by Fakultas Keguruan dan Ilmu Pendidikan, Universitas Samudra, Langsa-Aceh.

Wagner, C., Kawulich, B., \& Garner, M. (2019). A mixed research synthesis of literature on teaching qualitative research methods. SAGE Open, 9(3). https://doi.org/10.1177/2158244019861488

Wamalwa, E. J., \& Wamalwa, E. W. (2014). Towards the utilization of instructional media for effective teaching and learning of English in Kenya.

Washburn, E. K., Binks-Cantrell, E. S., Joshi, R. M., Martin-Chang, S., \& Arrow, A. (2016). Preservice teacher knowledge of basic language constructs in Canada, England, New Zealand, and the USA. Annals of dyslexia, 66(1), 7-26. https://doi.org/10.1007/s11881-016-0128-0

Williford, A. P., Maier, M. F., Downer, J. T., Pianta, R. C., \& Howes, C. (2013). Understanding how children's engagement and teachers' interactions combine to predict school readiness. Journal of Applied Developmental Psychology, 34(6), 299-309. https://doi.org/10.1016/j.appdev.2013.05.002

Wixson, K. K. (2017). An interactive view of reading comprehension: Implications for assessment. Language, Speech, and Hearing Services in Schools, 48(2), 77-83. https://doi.org/10.1044/2017_LSHSS-16-0030

Woolley. (2010). A Multiple Strategy Framework Supporting Vocabulary Development for Students with Reading Comprehension Deficits. Australasian Journal of Special Education, 34, 119-132. https://doi.org/10.1375/ajse.34.2.119

\section{Copyrights}

Copyright for this article is retained by the author(s), with first publication rights granted to the journal.

This is an open-access article distributed under the terms and conditions of the Creative Commons Attribution license (http://creativecommons.org/licenses/by/4.0/). 